\title{
Cuantificación de emisiones de metano en digestores anaerobios rurales empleados en el tratamiento de residuos agrícolas
}

\author{
Bernd Weber ${ }^{a^{*}}$, Sabrina Eichenauer ${ }^{b}$ \\ ${ }^{a}$ Universidad Autónoma del Estado de México, C.P 50130, Toluca, Edo. Mex. \\ ${ }^{b}$ Technische Hochschule Mittelhessen. \\ *bweber@uamex.mx.
}

Recibido 10 septiembre 2013, Aceptado 30 noviembre 2013

\section{Resumen}

La producción de biogás a partir de residuos agrícolas en zonas rurales es muy común en varios países, y México no es la excepción, el biogás generado se aprovecha para cubrir la demanda de energía calórica para cocinar y uso de agua caliente en el hogar. Sin embargo, la emisión de gases de efecto invernadero puede causar mayor impacto si éstas se comparan con el beneficio logrado por el reemplazo de los combustibles fósiles en el sitio. El presente estudio evaluó el desempeño de un biodigestor "in situ", mediante un balance de masas analizando los productos de entrada y los de salida. El estudio muestra que aun en condiciones de temperatura extrema, los digestores de estiércol sin calentamiento tienen una alta tasa de degradación, alcanzando remociones de la materia orgánica mayor al 75\%. Sin embargo, el potencial de producción de biogás muchas veces excede la demanda en el sitio y por tal motivo se recomienda implementar sistemas a pequeña escala que permiten utilizar los excedentes para la electrificación y de esa manera evitar su liberación hacia la atmósfera.

Palabras clave: Gases de efecto invernadero, Biodigestores rurales, Estiércol.

\section{Introducción}

Cada día, se genera más evidencia de que la bioenergía reemplazará a los combustibles fósiles con el fin de avanzar hacia un desarrollo sustentable, el cual restringe el uso de dichos combustibles y sus emisiones. Para México tiene importancia el desarrollo de los combustibles renovables porque su producción de petróleo crudo se está disminuyendo [1], sin embargo, otros países cuentan con recursos más abundantes todavía [2], por esta razón el desarrollo sustentable requiere un mayor enfoque en la reducción de emisiones. El escenario 450 propuesto por la Agencia Internacional de Energía (IEA por sus siglas en inglés) describe metas para mantener la concentración del dióxido de carbono en la atmósfera debajo de las 450 ppm hasta el año 2050, valor que nos asegurará un calentamiento no mayor de $\operatorname{los} 2{ }^{\circ} \mathrm{C}$ [3]. Bajo este escenario el uso de recursos fósiles tendrá que ser reducido debido a las emisiones de dióxido de carbono que generan.

La producción de bioenergéticos de manera sustentable es un gran reto, ya que existen emisiones (tal vez importantes) que se asocian a su producción. Tal es el caso de la fabricación de fertilizantes, los procesos microbiológicos en el suelo, la perdida de materia orgánica por el cambio de uso de suelo y también el procesamiento de los bioenergéticos. Recientemente, el ganador de premio nobel P. Crutzen, publicó que la producción de bioenergéticos puede ser incluso contraproducente para el efecto invernadero en la región de Europa central debido sobre todo a las emisiones del gas óxido de nitrógeno $\left(\mathrm{N}_{2} \mathrm{O}\right)$ que se libera por los procesos de denitrificación en los suelos [4].
La producción del biometano (biogás) en digestores anaerobios se considera muy adecuada porque es uno de los pocos procesos que pueden utilizar como materia prima los residuos. Por esa razón, también México sigue en la tendencia actual de la implementación de digestores de anaerobios para el tratamiento de residuos agrícolas como han demostrado países como China e India con mucho éxito desde varias décadas. Por otro lado, para la producción del biometano (biogás) proveniente de los digestores anaerobios de manera sustentable, se deben considerar adicionalmente las fugas de este gas que se producen durante su manejo ya que su efecto invernadero es un factor de 23 veces mayor al del dióxido de carbono por lo que se debe tener un control cuidadoso durante la producción y uso [5].

Con fines de poder estimar la magnitud de las emisiones que pueden provenir de los biodigestores de pequeña escala, el estudio analiza basando en las características de operación el potencial de producción de biogás y balancea el impacto de reducción o aumento en la emisión de gases de efecto invernadero por la utilización de esa tecnología y reemplazando combustibles fósiles.

\section{Parte experimental}

Se utilizó un digestor de $40 \mathrm{~m}^{3}$ tipo "biobolsa" para digerir los residuos de 60 puercos en engorda. Para el balance de masas se midió el contenido de sólidos volátiles a la entrada y salida del biodigestor mediante la técnica de incineración de residuos. 


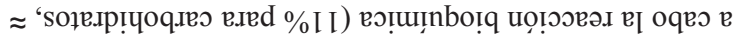

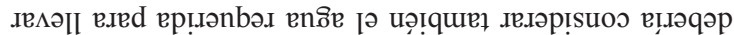

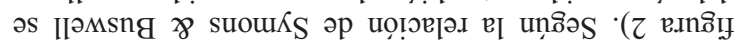

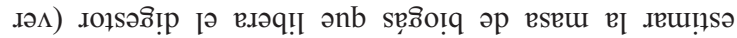

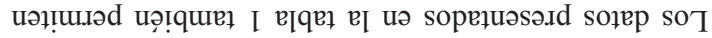

\begin{tabular}{|c|c|c|c|c|c|}
\hline 18 & 69 & $0^{\circ} \mathrm{Z}$ & 89 & 16 & $\forall \forall W$ \\
\hline †8 & ऽ9 & $9^{\prime} z$ & $8 \mathrm{~L}$ & tl & ગા \\
\hline GL & 79 & $\varepsilon^{\prime} z$ & $\nabla L$ & $L L$ & רח \\
\hline$(\%)$ & (\%) & (\%) & (\%) & (\%) & \\
\hline $\begin{array}{l}\text { ^u০J } \\
\text { әр }\end{array}$ & $\begin{array}{l}\text { op!|osolq } \\
\text { uә }\end{array}$ & $\begin{array}{l}\text { op!|ọso!q } \\
\text { uə }\end{array}$ & $\begin{array}{l}\text { 아쏘sns } \\
\text { uә }\end{array}$ & $\begin{array}{c}\text { oleגsns } \\
\text { uə }\end{array}$ & səW \\
\hline ese $\perp$ & 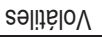 & sop!̣|os & 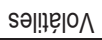 & sop!|os & \\
\hline
\end{tabular}

"esjoqoiq."

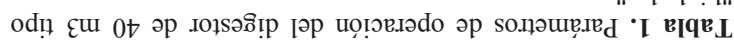

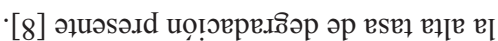

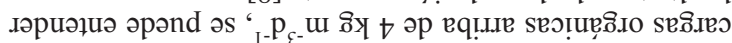

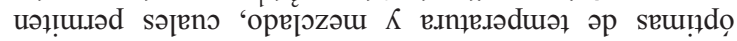

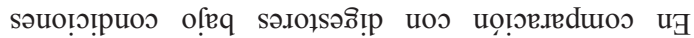
_. $\mathrm{p}_{\varepsilon}$ u

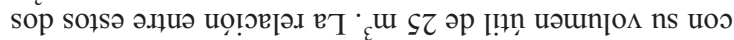
.

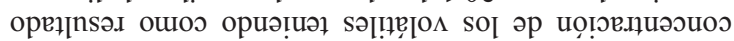

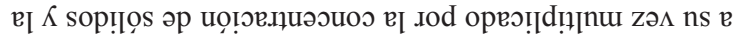
'sos.ənd 09 rod opeə!!

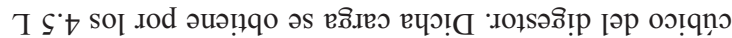

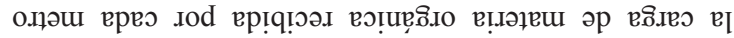

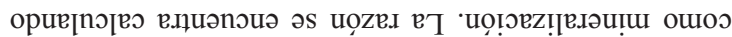

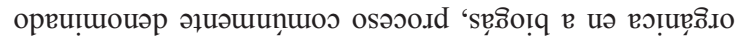

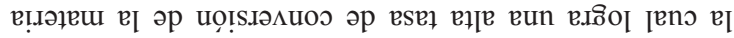

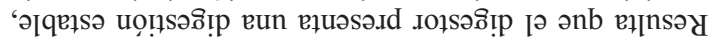

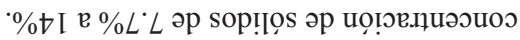

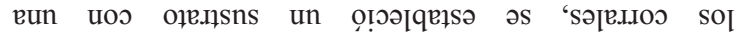

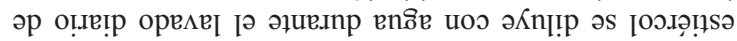

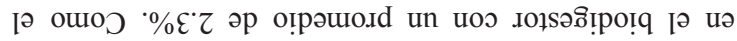

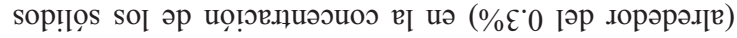

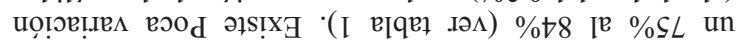

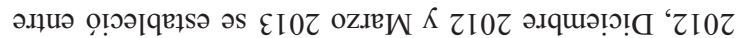
o!̣n

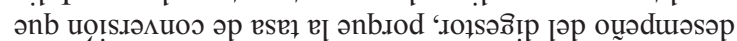

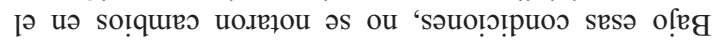

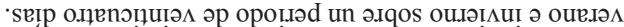

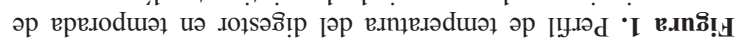

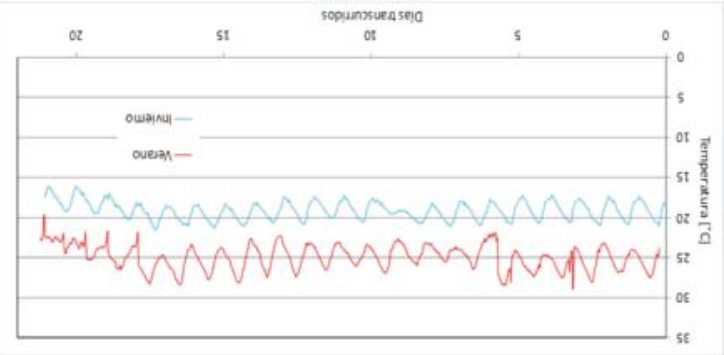

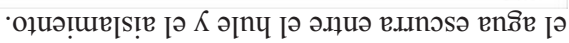

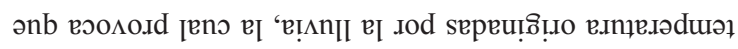

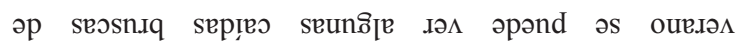

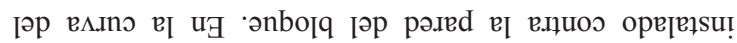

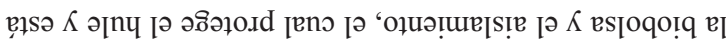

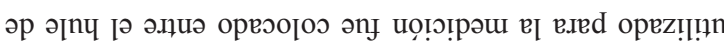

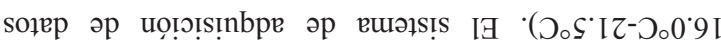

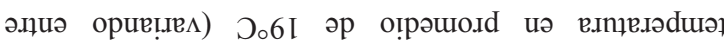

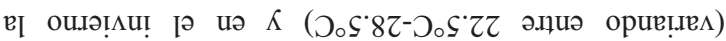

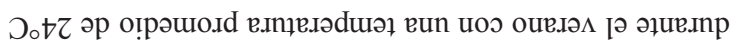

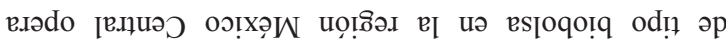

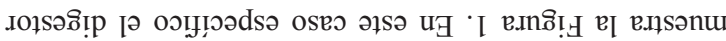

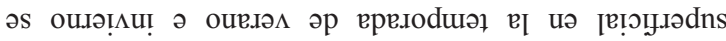

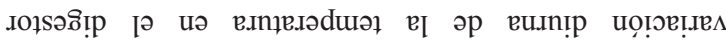

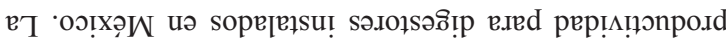

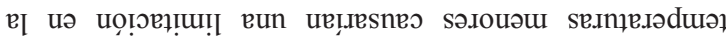

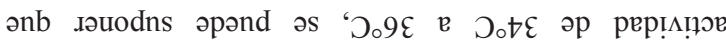

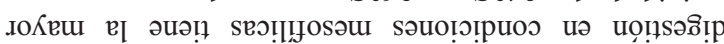

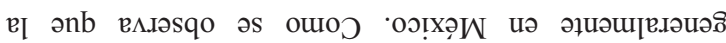

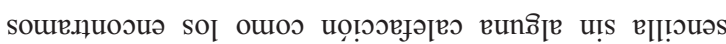

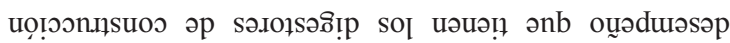

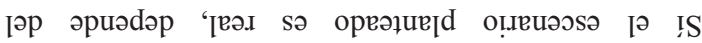

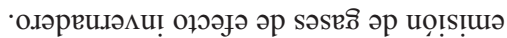

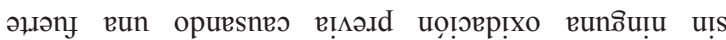
о! $\Lambda$ !

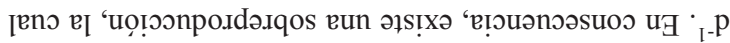

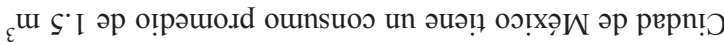

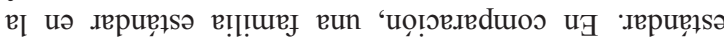

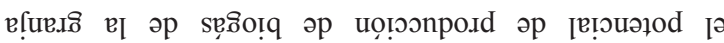

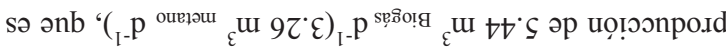

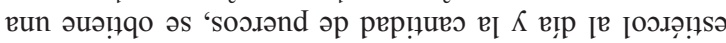

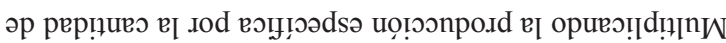

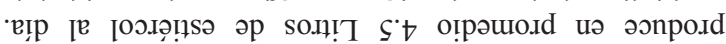

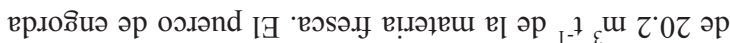

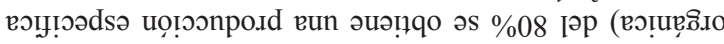
вцәреш) sәџฺฺ

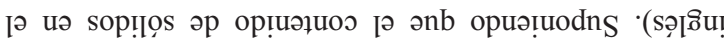

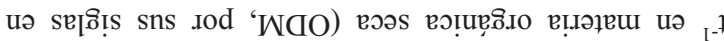

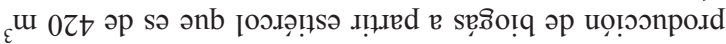

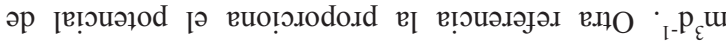

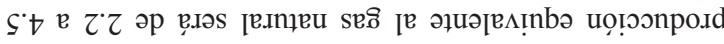

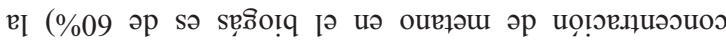

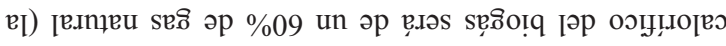
rəpod

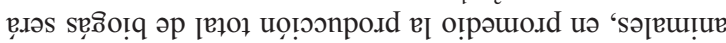

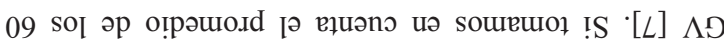

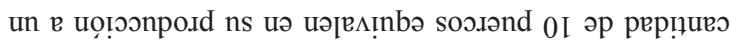

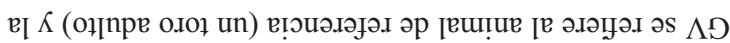

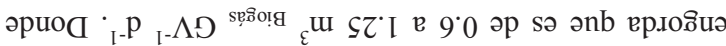

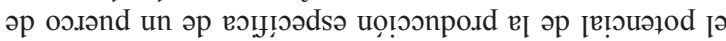

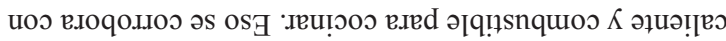

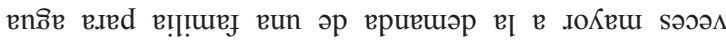

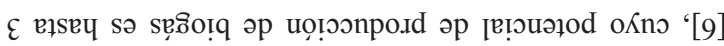

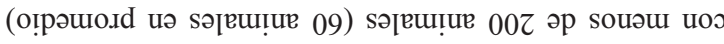

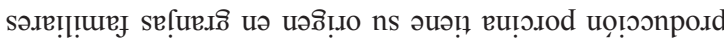

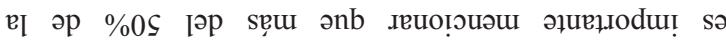

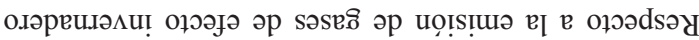

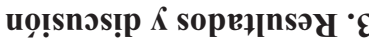


$54 \%$ para grasas y $\approx-20 \%$ para proteínas) [9], pero en este caso, con una composición de la materia seca de aproximadamente de $9 \%$ de grasas, $24 \%$ de proteínas y más del $32 \%$ de carbohidratos el factor del agua es depreciable [7]. Las ecuaciones asociados a la imagen calculan la producción específica del biogás en litros por kg DM y kg ODM considerando una concentración del metano de $55 \%$

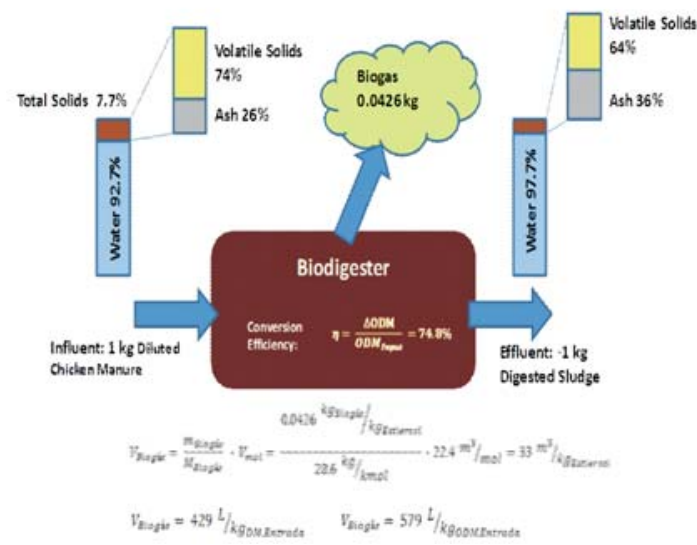

Figura 2. Balance de masas para un digestor anaerobio con estiércol de cerdo como sustrato.

Como se ha demostrado, los digestores sí tienen una mayor tasa de degradación, por lo cual se tiene la certeza que una sobre producción es muy probable. Para evaluar el impacto de la emisión de gases de efecto invernadero comúnmente se trabaja con un escenario de referencia. Como es complejo de referenciar el manejo del estiércol e incluso no existen datos muy precisos sobre la emisión de $\mathrm{N}_{2} \mathrm{O}$ al momento de fertilizar con estiércol en comparación con otro fertilizante, se hace en la figura 3 una comparación con paja de trigo como sustrato para el biodigestor.

El manejo de la paja de trigo en el escenario convencional es que la paja de trigo se quema en la milpa y como energético se utiliza la antracita. La incineración de esos productos genera $2.87 \mathrm{~kg}$ de $\mathrm{CO} 2$ equivalentes. La comparación será la conversión de $1 \mathrm{~kg}$ de paja de trigo en un biodigestor, el cual en su balance produce $0.21 \mathrm{~kg}$ residuos no digeridos (se considera su oxidación posterior en el suelo), $0.6 \mathrm{~kg}$ de biogás con aprovechamiento térmico en el sitio y una fuga de biogás de $0.19 \mathrm{~kg}$ la cual se libera al medio ambiente. Debido al gas metano con una concentración del $55 \%$ con un impacto 23 veces mayor que el dióxido de carbono como gas de efecto invernadero, la franja saliendo del digestor es muy delgada pero después se multiplica causando casi el $50 \%$ de todas las emisiones. El balance quiere decir que con una fuga de biogás del 34\% las emisiones para ambos escenarios serán iguales, es decir, de $2.87 \mathrm{~kg}$ $\mathrm{CO}_{2 \mathrm{eq}} \mathrm{kg}^{-1}$ Paja.

\section{Conclusiones}

El manejo de residuos en biodigestores rurales proporciona a los campesinos una fuente de energía renovable. Sin embargo, al contrario de los digestores implementados en la India y en China, los cuales son de menor capacidad, se genera una sobreproducción, la cual, al momento de ser liberado al medio ambiente empeora el balance de la emisión de gases de efecto invernadero.

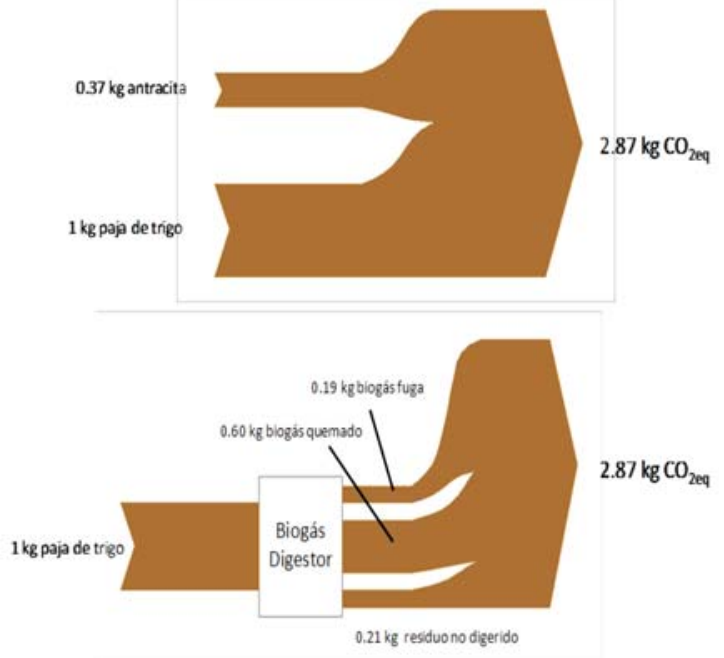

Figura 3. Comparación de dos diferentes escenarios de emisión para el tratamiento de paja de trigo por incineración en la milpa y la conversión en un digestor de biogás.

Así, es importante implementar buenas prácticas para el manejo de biogás, por ejemplo, quemarlo en lugar de dejarlo salir por la válvula de alivio. También a corto plazo es muy recomendable implementar sistemas de incineración con aprovechamiento para la producción de energía eléctrica a pequeña escala.

\section{Agradecimientos}

Agradecemos al señor Inocencio Rojo Mejía por facilitar el acceso a su biodigestor para la realización de la toma de muestras y realizar mediciones. El proyecto en curso es registrado como proyecto de investigación bajo el esquema PROMEP con el número de registro /103.5/12/8048.

\section{Referencias}

1. Balance Nacional de Energía. http://www.sener.gob.mx/res/PE y DT/ pub/2012/BNE_2011.pdf (Acceso: 04.07.2013).

2. Kausch, P. Gutzmer, J. Bertau, M. Matschullat, J.Energie und Rohstoffe. Heidelberg: Spektrum Akademischer Verlag, 2011.

3. IEA: World Energy Outlook 2010. International Energy Agency. http://www.worldenergyoutlook.org/ (Acceso: 12.03.2013).

4. Reay, D.S. Davidson, E.A. Smith, K.A.; Smith, P.Melillo, J.M.; Dentener, F. Crutzen, P. J. Global agriculture and nitrous oxide emissions. Nature Climate Change 2012, 2(6), 410-416.

5. Philander, S. G. Encyclopedia of global warming and climate change. Los Angeles: SAGE, 2008.

6. SAGARPA http://www.sagarpa.gob.mx/ (Acceso:

12.03.2013).

7. Eder, B. Krieg, A. Biogas - Praxis. 2012, Staufen, oekobuch Verlag

8. Deublein, D. Steinhauser, A. Biogas from waste and renewable resources. An Introdution. 2008, Weinheim, VCHWiley.

9. Symons, G.E, Buswell, A.M. The methane fermentation of carbohydrates. J. Am. Chem. Soc.1993, 5(55), 2028-2036. 